body mass index) [1]. To date, there is little information about changes in severity in accordance with patient age.

Objectives: The aim of this study was to investigate variations in symptom severity in FM patients according to age categories.

Methods: A cross-sectional study of adult FM patients diagnosed according to the American College of Rheumatology 2010/2011 criteria was performed. The case series was included from an Italian national registry [2]. Patients were grouped according to five age categories: $18-40$ years, $41-50$ years, 51-60 years, 61-70 years, over 71 years. Symptom severity was assessed through the revised Fibromyalgia Impact Questionnaire (FIQR) and domains, including FIQR physical function (items 1-9), FIQR health status (items 10-11), and FIQR symptoms (items 12-21). Between-group characteristics were analysed using one-way analysis of variance (ANOVA).

Results: This study included a total of 2889 patients, 403 aged 18-40 years, 756 aged 40-50 years, 1035 aged 50-60 years, 528 aged 60-70 years, and 167 over 70 years, respectively. The mean (standard deviation [SD]) score of the total FIQR was 52.68 (11.82). Total FIQR and individual domains all showed a normal distribution. Analysing the data by age category, there were statistically significant differences between the categories for the total FIQR $(p=0.030)$. The age categories with the highest disease severity were those above 71 years (FIQR 62.14, SD 22.45), and between 51-60 years (FIQR 60.31, SD 22.89) (Table 1). Significant differences between age categories were also found for the domains physical function $(p=0.006)$ and health status $(p=0.012)$, but not for the domain symptoms $(p=0.164)$.

Table 1. Mean values of FIQR total score and domains according to age categories.

\begin{tabular}{|c|c|c|c|c|c|c|}
\hline FIQR and domains & $18-40$ years & s $41-50$ years & $51-60$ years & $61-70$ years & $\geq 71$ years & $p^{*}$ \\
\hline FIQR total, mean (SD) & $\begin{array}{l}57.90 \\
(21.76)\end{array}$ & $\begin{array}{l}59.25 \\
(23.30)\end{array}$ & $\begin{array}{l}60.31 \\
(22.89)\end{array}$ & $\begin{array}{l}57.13 \\
(23.59)\end{array}$ & $\begin{array}{l}62.14 \\
(22.45)\end{array}$ & 0.030 \\
\hline $\begin{array}{l}\text { FIQR physical function, } \\
\text { mean (SD) }\end{array}$ & $15.51(7.56)$ & $16.44(7.77)$ & $16.77(7.51)$ & $15.96(7.82)$ & $17.68(7.26)$ & 0.006 \\
\hline $\begin{array}{l}\text { FIQR health status, } \\
\text { mean (SD) }\end{array}$ & $11.19(5.85)$ & $11.24(5.99)$ & $11.49(5.93)$ & 10.57 & ) $12.21(5.97)$ & ) 0.012 \\
\hline $\begin{array}{l}\text { FIQR symptoms, mean } \\
\text { (SD) }\end{array}$ & $\begin{array}{l}31.32 \\
(10.48)\end{array}$ & $31.56(11.32)$ & 2)32.10 (11.01) & $\begin{array}{l}30.68 \\
(11.47)\end{array}$ & $\begin{array}{l}32.24 \\
(11.34)\end{array}$ & 0.164 \\
\hline
\end{tabular}

Abbreviations and legend. FIQR = revised Fibromyalgia Impact Questionnaire; SD = standard deviation; ${ }^{*}$ = one-way analysis of variance (ANOVA).

Conclusion: Distinguishing the disease severity in FM patients according to age categories, a bimodal distribution emerges, with the disease severity being greatest in patients over 71 years and in the 51-60 years decade. The main differences in severity, according to what can be detected through the FIQR, are attributable to the domains physical function and health status, which show higher scores in the two classes with higher severity.

REFERENCES:

[1] Sarzi-Puttini P et al., Fibromyalgia: an update on clinical characteristics, aetiopathogenesis and treatment. Nat Rev Rheumatol 2020; 16: 645660.

[2] Salaffi F et al., The Italian Fibromyalgia Registry: a new way of using routine real-world data concerning patient-reported disease status in healthcare research and clinical practice. Clin Exp Rheumatol 2020; Suppl 123: 65-71.

Acknowledgements: Società Italiana di Reumatologia (SIR) and Italian Ministry of Health

Disclosure of Interests: None declared

DOI: 10.1136/annrheumdis-2021-eular.1507

\section{AB0717 1 PREVALENCE OF MIGRAINE AND NEUROPATHIC PAIN AMONG PATIENTS WITH RHEUMATIC DISEASES}

S. Miladi ${ }^{1}$, M. Yasmine ${ }^{1}$, A. Fazaa ${ }^{1}$, S. Mariem ${ }^{1}$, K. Ouenniche ${ }^{1}$, L. Souebni ${ }^{1}$, S. Kassab ${ }^{1}$, S. Chekili ${ }^{1}$, K. Ben Abdelghani ${ }^{1}$, A. Laatar ${ }^{1} .{ }^{1}$ Mongi Slim Hospital, Rheumatology, Tunis, Tunisia

Background: Pain in rheumatic diseases $(R D)$ is primarily due to mechanical or inflammatory mechanism, but neuropathic pain (NP) component is yet to be fully evaluated and described, with a particular attention to the distinction with nociceptive pain [1].

Objectives: The aim of our study was to assess the prevalence of migraine and neuropathic pain in patients with $R D$ and to explore factors associated with NP.

Methods: Prospective study including patients with rheumatoid arthritis (RA) and spondylarthritis (SpA) were invited to complete a validated self-assessment questionnaires. Sociodemographic data as well as disease related characteristics were recorded. Migraine was diagnosed according to the IHS migraine diagnostic criteria. NP was evaluated using DN4 (Douleur Neuropathique 4 Questions) and Pain DETECT questionnaire (PDQ). Neuropathic pain was retained in case of a total score of 4 or more at DN4-interview questionnaire or a score $\geq 19$ with the PDQ.

Results: A total of 60 patients with RD were included (42 RA/18 SpA). Females outnumbered males (sex-ratio=1.7). The mean age was $51.3 \pm 13.1$ years [18-75] and the mean disease duration was $11.9 \pm 5.6$ [1-23] years. The prevalence of migraine was $15 \%$. This latter was higher among women than men and among RA patients than SpA (18\% vs $9 \%, 16.6 \%$ vs $11.2 \%)$ with no statistically significant correlation ( $p=0,329,0,581$ respectively). Parameters associated with a higher prevalence of migraine were an older age $(p=0,042)$. However, there was no correlation between the presence of migraine and the type of the $\mathrm{RD}$, disease duration or the level of anxiety ( $p=0,059, p=0,459$ respectively). Chronic pain with neuropathic characteristics was found in $21.7 \%$ with the DECT score and $16.7 \%$ with DN4 questionnaire. NP was most prevalent among patients with comorbidities $(28.5 \%$ vs $6 \%, p=0.021)$ and with higher body mass index $(p=0.01)$. Prevalence was significantly higher in the RA group (19\%) than in the SpA group $(11 \%)$ without a statistically significant correlation $(p=0.45)$. Similarly, NP was not associated with Salazopyrine intake $(p=0.9)$.

Conclusion: We found a high prevalence of migraine and NP in our sample of patients with RD. It seems therefore important to check the presence of migraine or NP especially in patients with comorbidities and older ones.

\section{REFERENCES:}

[1] Bailly F, Cantagrel A, Bertin P, et al. Part of pain labelled neuropathic in rheumatic disease might be rather nociplastic. RMD Open. 2020;6:e001326.

Disclosure of Interests: None declared

DOI: 10.1136/annrheumdis-2021-eular.2132

\section{AB0718 1 ASSESSMENT OF SEXUAL DYSFUNCTION IN WOMEN AND MEN WITH FIBROMYALGIA SYNDROME}

G. Mouna $^{1}$, J. Mahbouba ${ }^{1}$, S. Zrour $^{1}$, I. Bejia ${ }^{1}$, M. Touzi ${ }^{1}$, N. Bergaoui ${ }^{1}$

${ }^{1}$ Rhumatology Departement of CHU Fattouma Bourguiba, Rhumatology

Departement of CHU Fattouma Bourguiba, Monastir, Tunisia

Background: Fibromyalgia syndrome is a chronic musculoskeletal disease which compromises physical, mental, and sexual health. Although concerns related to sexuality are commonly reported, the literature on sexual functioning in patient with fibromyalgia is limited to female patients.

Objectives: The aim of our study is to identify sexual dysfunction in women and men with fibromyalgia syndrome compared with patients with rheumatoid arthritis.

Methods: This is a cross-sectional comparative study: ' 34 patients with fibromyalgia syndrome compared to 100 patients with rheumatoid arthritis' conducted in the rheumatology department of $\mathrm{CHU}$ Fattouma Bourguiba de Monastir over a period from February to November 2017. We used the Female Sexual Function Index (FSFI) and the Sexual Health Inventory for Men (SHIM).

Results: Our sample comprised 34 patients with fibromyalgia (31 females and 3 males) and 100 patients with rheumatoid arthritis (58 females and 15 males) Sexual dysfunction was present in $100 \%$ of female patients with fibromyalgia syndrome compared to $60 \%$ of female patients with rheumatoid arthritis. Female patients with fibromyalgia syndrome had a decreased FSFI score: $10,3 \pm 8,74$ versus $16,86 \pm 8,87$ in the rheumatoid arthitis group with $p=0.001$. While among the male patients, we found no significant difference between the two groups.

Conclusion: Fibromyalgia syndrome had negative side effect on the sexual life of female patients. Recognition of this dysfunction and its inclusion in the multidisciplinary management of fibromyalgia must be part of the treatment.

\section{REFERENCES:}

[1] P. Romero-Alcalá et al., « Sexuality in male partners of womenwithfibromyalgiasyndrome: A qualitative study », PLoS One, vol. 14, $\mathrm{n}^{\circ} 11$, nov. 2019, doi: 10.1371/journal.pone.0224990.

[2] M. D. H. Besiroglu et M. D. M. Dursun, «The association betweenfibromyalgia and femalesexualdysfunction:asystematicreview and meta-analysis of observationalstudies », Int J ImpotRes, vol. 31, n 4, p. 288-297, juill. 2019, doi: 10.1038/s41443-018-0098-3.

[3] T. M. Matarín Jiménez, C. Fernández-Sola, J. M. Hernández-Padilla, M. Correa Casado, L. H. Antequera Raynal, et J. Granero-Molina, « Perceptions about the sexuality of womenwithfibromyalgiasyndrome:aphenomenologicalstudy », J Adv Nurs, vol. 73, n 7, p. 1646-1656, juill. 2017, doi: 10.1111/ jan.13262.

[4] L. Bazzichiet al., « Fibromyalgia and sexualproblems », Reumatismo, vol. 64, $n^{\circ} 4$, p. 261-267, sept. 2012, doi: 10.4081/reumatismo.2012.261.

Disclosure of Interests: None declared

DOI: 10.1136/annrheumdis-2021-eular.3721 